\title{
PENGARUH IMBALAN, PENGAWASAN, KONDISI KERJA, PENGEMBANGAN KARIER, PENGHARGAAN DAN KELOMPOK KERJA TERHADAP KEPUASAN KERJA PERAWAT PELAKSANA DI RUANG RAWAT INAP RUMAH SAKIT UMUM DAERAH TGK.CHIK DITIRO SIGLI
}

\author{
Tristi Yuanita
}

Fakultas Keguruan dan Ilmu Pendidikan

Universitas Jabal Ghafur

\section{A B S T R A K}

Kepuasan kerja perawat pelaksana merupakan aspek penting yang perlu mendapatkan perhatian dari rumah sakit dalam upaya peningkatan pelayanan kepada pasien. Apabila kepuasan kerja perawat terpenuhi, maka perawat cenderung akan memiliki motivasi yang tinggi dalam bekerja, sebaliknya apabila kepuasan kerja rendah akan mengakibatkan, ketidakhadiran, pemogokan dan tindakan-tindakan lain yang merugikan rumah sakit. Penelitian ini bertujuan menguji pengaruh imbalan, pengawasan, kondisi kerja, pengembangan karier, penghargaan, dan kelompok kerja terhadap kepuasan kerja.

Penelitian ini menggunakan desain cross sectional dengan pendekatan kuantitatif di RSUD Tgk. Chik Ditiro Sigli pada bulan September sampai Oktober 2015. Sampel berjumlah 57 perawat pelaksana, dengan menggunakan kuesioner. Metode analisis data yaitu univariat, bivariat dan multivariat dengan menggunakan uji regresi linier berganda.

Hasil penelitian menunjukan bahwa imbalan, pengawasan, kondisi kerja, penghargaan, kelompok kerja, tidak berpengaruh signifikan terhadap kepuasan kerja. Sedangkan pengembangan karier berpengaruh signifikan terhadap kepuasan kerja.Variabel yang berpengaruh paling dominan adalah pengembangan karier.

Disarankan kepada pimpinan rumah sakit untuk memberikan kesempatan kepada perawat pelaksana meningkatkan pendidikan, pengalokasian dana untuk pelatihan, menyusun kebijakan yang jelas untuk kenaikan pangkat dan pemberian kesempatan yang sama terhadap perawat pelaksana untuk menduduki jabatan stuktural.

\section{A B S TRACT}

Job satisfaction of nurses is an important aspect that needs to get the attention of the hospital in an effort to improve services to patients. If the job satisfaction of nurses are met, then the nurse will tend to have high motivation to work, otherwise if would lead to lower job satisfaction, absenteeism, strikes and other acts that harm the hospital. This study aims to examine the effect of compensation, supervision, working conditions, career development, rewards, and the working group on job satisfaction.

This study used cross sectional design with quantitative approach in the General Hospital of TGK. Chik Ditiro Sigli in September and October 2015. The sample amounted to 57 nurses, using a questionnaire. Data analysis methods are univariate, bivariate and multivariate by using multiple linear regression.

The results showed that in exchange, supervision, working conditions, rewards, working groups, no significant effect on job satisfaction. While the career development of a significant effect on job satisfaction. Influential variable is the most dominant career development.

Suggested to the leadership of the hospital to provide an opportunity for nurses to improve education, allocation of funds for training, draw up a clear policy for the promotion and provision of equal opportunities to nurses for structural positions.

\section{PENDAHULUAN}

Ketatnya persaingan dalam pemberian jasa pelayanan kesehatan oleh rumah sakit saat ini, membutuhkan peninjauan kembali sistem manajemen yang digunakan. Karena pada saat ini rumah sakit tidak lagi dipandang sebagai usaha sosial yang dapat dikelola begitu saja, tetapi lebih merupakan suatu industri jasa (Kaplan dan Norton, 1996).

Jurnal Sains Riset | Volume VIII Nomor I 
Mengelola sumber daya di rumah sakit merupakan tugas yang rumit dan penuh tantangan. Sebagai industri jasa, peran sumber daya manusia sangat vital (Soeroso, 2003). Jumlah tenaga kerja di rumah sakit berdasarkan dari data Badan Pengembangan dan Pemberdayaan Sumber Daya Manusia Kesehatan (BPPSDMK)Kementerian Kesehatan Republik Indonesia pada tahun 2012 adalah 668.552 orang dengan $32,91 \%$ diantaranya adalah perawat . Sedangkan Gillies (1996) menyatakan bahwa $40 \%-60 \%$ pelayanan kesehatan di rumah sakit merupakan pelayanan keperawatan.

Pelayanan yang berkualitas dan bermutu tinggi, di rumah sakit dapat tercapai salah satu dengan cara meningkatkan kepuasan kerja karyawannya, khususnya dari perawat pelaksana sebagai tenaga kesehatan terbanyak dalam sebuah rumah sakit, karena kepuasan kerja perawat pelaksana yang tinggi akan meningkatkan kinerja mereka sehingga akan terselenggara pelayanan kesehatan di rumah sakit yang bermutu tinggi (Marquis \& Huston, 2010).

Kepuasan kerja yang rendah, selain mempengaruhi prestasi dan produktifitas kerja juga dapat menimbulkan tingginya kemangkiran, protes dan tidak berkerja sesuai jam kerja yang telah ditentukan oleh rumah sakit, sehingga program yang telah direncanakan tidak dapat terlaksana dengan baik. Keadaan ini menyebabkan rendahnya kepercayaan dari pelanggan internal maupun eksternal terhadap rumah sakit karena tidak dapat memberikan pelayanan kepada mereka dengan baik.

Perbaikan mutu pelayanan kepada pelanggan internal rumah sakit dapat dilakukan salah satunya dengan cara melakukan penelitian kepuasan kerja perawat pelaksana di ruang rawat inap RSUD Tgk.Chik Ditiro. Dari hasil pengamatan pendahuluan yang dilakukan oleh peneliti didapatkan fenomena adanya perawat pelaksana yang masuk kerja tidak tepat waktu, meninggalkan ruang tempat kerja saat sedang bertugas (ketidakdisiplinan waktu seperti permisi ke kantin, ada urusan sebentar untuk menjemput anak sekolah atau urusan lain), ketidakhadiran dinas tanpa ada pemberitahuan, perawat merasa tidak dihargai baik oleh dokter, teman sekerja, pembagian uang jasa medis atau insentif yang dirasakan tidak sesuai dengan beban kerja di ruangan sehingga ada sebagian perawat pelaksana berasumsi lebih baik bertugas di poliklinik dibandingkan di ruang rawat inap karena di poliklinik tidak ada jaga malam, tetapi jasa medis atau insentif lebih besar, selain itu ketidakpuasan kerja tersebut juga berasal dari kesempatan untuk promosi yang sangat terbatas dan kurang transparan, yang menurunkan semangat perawat pelaksana untuk meningkatkan kualitas kerja. Perawat pelaksana merasa tidak perlu memberikan asuhan keperawatan dengan baik dan meningkatkan wawasan serta keterampilan mereka karena tidak akan mempengaruhi karier mereka sama sekali. Kondisi tersebut merupakan bentuk gejala atau dampak dari ketidakpuasan kerja dari perawat pelaksana diruang rawat inap RSUD Tgk. Chik Ditiro Sigli. Berdasarkan hasil dari penelitian pendahuluan tersebut, peneliti tertarik melakukan penelitian di RSUD Tgk.Chik Ditiro, Sigli dengan judul "Pengaruh Imbalan, Pengawasan, Kondisi Kerja, Pengembangan Karier, Penghargaan, dan Kelompok Kerja Terhadap Kepuasan Kerja Perawat Pelaksana Di Ruang Rawat Inap Rumah Sakit Umum DaerahTgk.Chik Ditiro Sigli Tahun 2015”.

\section{PERUMUSAN MASALAH}

Berdasarkan latar belakang yang telah diuraikan, maka permasalahan dalam penelitian ini adalah: bagaimana pengaruh imbalan, pengawasan, kondisi kerja, pengembangan karier, penghargaan dan kelompok kerja terhadap kepuasan kerja perawat pelaksana di ruang rawat inap rumah sakit umum daerah Tgk.Chik Ditiro Sigli tahun 2015?

\section{TUJUAN PENELITIAN}

Menganalisis pengaruh imbalan, pengawasan, kondisi kerja, pengembangan karier, penghargaan dan kelompok kerja terhadap kepuasan kerja perawat pelaksana di ruang rawat inap rumah sakit umum daerah Tgk.Chik Ditiro Sigli tahun 2015.

\section{MANFAAT PENELITIAN}

1. Diharapkan dapat menjadi bahan masukan bagi RSUD Tgk.Chik Ditiro Sigli dalam membuat kebijakan dan peraturan tentang aspek-aspek yang berkaitan dengan kepuasan kerja perawat pelaksana, agar visi dan misi rumah sakit dapat tercapai.

2. Diharapkan dapat menjadi bahan masukan bagi perawat pelaksana di ruang rawat inap, untuk selalu melakukan perbaikan dalam melaksanakan asuhan

Jurnal Sains Riset | Volume VIII Nomor I 
keperawatan agar mendapatkan hak dan kepuasan kerja di rumah sakit.

\section{METODE PENELITIAN}

Penelitian ini merupakan penelitian kuantitatif desain CrossSectional. Penelitian dilakukan di di RSUD Tgk.Chik Ditiro Sigli. Waktu penelitian, dimulai dari bulan September sampai dengan Oktober 2015.

Populasi dalam penelitian ini adalah seluruh perawat pelaksana, di 10 ruang rawat inap RSUD Tgk Chik Ditiro Sigli, yang bejumlah 139 orang yang berstatus pegawai negeri sipil (PNS), minimal bekerja 1 tahun di rumah sakit dengan sampel minimal sebanyak 57 orang tenaga keperawatan pelaksana di ruang rawat inap.

Metode pengumpulan data yang digunakan adalah survey, studi dokumentasi dan kepustakaan.

Instrumen yang digunakan dalam pengumpulan data penelitian adalah kuesioner terstruktur dan disesuaikan dengan variabel penelitian.

Analisa data dalam penelitian ini diolah dengan menggunakan SPSS Versi 22.

\section{HASIL DAN PEMBAHASAN}

Gambaran hasil penelitian tentang imbalan di rumah sakit ini yaitu, 53 perawat (93\%) berpendapat bahwa pemberian imbalan sudah diberikan secara adil, hanya 4 perawat $(7 \%)$ perawat pelaksana mempunyai pendapat bahwa pemberian imbalan masih tidak adil. Untuk meningkatkan kepuasan terhadap imbalan ini diharapkan rumah sakit kedepannya mampu meningkatkan rasa keadilan dalam pemberian insentif yang jelas agar kedepannya tingkat kepuasan perawat menjadi $100 \%$, yaitu dengan mempertimbangkan kinerja, pendidikan, dan keterampilan. Menurut Darodjat (2015), imbalan yang diberikan dalam bentuk gaji atau insentif kepada karyawan atas kontribusi mereka dapat membantu organisasi untuk mencapai tujuan, apabila karyawan yang bekerja di organisasi tersebut merasa menerima imbalan secara adil.

Dari hasil penelitian rata-rata jawaban perawat pelaksana $53(93 \%)$ berpendapat bahwa pengawasan yang dilakukan atasan mereka baik, sedangkan $4(7 \%)$ perawat pelaksana berpendapat bahwa pengawasan kurang baik. Untuk meningkatkan kepuasan terhadap pengawasan maka pimpinan yang ada di rumah sakit harus, memberi arahan dan mengawasi para pekerja pada tingkat terbawah sebuah organisasi (Winardi, 2004)

Hasil penelitian tentang kondisi kerja diketahui rata-rata jawaban perawat pelaksana 44 $(77,2 \%)$ berpendapat bahwa bahwa kondisi kerja mendukung kerja mereka, $13(22,8 \%)$ perawat pelaksana berpendapat tidak mendukung. Masih adanya perawat yang berpendapat bahwa kondisi tempat kerja tidak mendukung, maka diharapkan rumah sakit mempu meningkatkan kepuasan kerja perawat pelaksana yang berhubungan dengan kondisi kerja. Karena Kondisi kerja yang aman, nyaman, bersih, penataan ruangan kerja yang rapi, fasilitas kerja yang baik, dan memadai mampu membawa dampak positif pada kinerja perawat pelaksana.Karena dapat menimbulkan rasa nyaman dan tenang saat berkerja, baik kenyaman pribadi maupun untuk memudahkan mengerjakan tugas dengan baik.Selain keadaan lingkungan fisik, kesesuaian pekerjaan, adanya jaminan kesehatan, fasilitas yang bersih, modern dan dengan peralatan yang memadai (Robbins, 2008).

Hasil penelitian berdasarkan pendapat perawat pelaksana terhadap pengembangan karier di RSUD Tkg Chik Ditiro Sigli yaitu ratarata jawaban perawat pelaksana 37 (34,9\%) berpendapat bahwa pengembangan karier di RSUD Tgk.Chik Ditiro Sigli sudah adil, sedangkan $20(35,1 \%)$ perawat pelaksana merasa belum adil.

Hasil penelitian yang telah dilakukan diperoleh bahwa pemberian penghargaan di RSUD Tgk. Chik Ditiro Sigli rata-rata jawaban perawat pelaksana $42(73,7 \%)$ berpendapat bahwa mereka merasa dihargai, sedangkan 20 $(35,1 \%)$ perawat pelaksana merasa tidak dihargai.

Dari hasil penelitian diperoleh gambaran bahwa kelompok kerja di RSUD Tgk. Chik Ditiro Sigli bahwa rata-rata jawaban perawat pelaksana 53 (93\%) berpendapat bahwa kelompok kerja di RSUD Tgk.Chik Ditiro Sigli sudah mendukung, sedangkan 4 (7\%) perawat pelaksana merasa tidak mendukung.

Tabel 1. Hubungan Imbalan, Pengawasan,

Kondisi Kerja, Pengembangan Karier, Penghargaan, Kondisi Kerja Terhadap Kepuasan Kerja Perawat Pelaksana di Ruang Rawat Inap RSUD Tgk Chik Ditiro Sigli Tahun 2015

Variabel Kepuasan Kerja




\begin{tabular}{lcc}
\hline & $\begin{array}{c}\text { Korelasi } \\
\text { Pearson }\end{array}$ & $\begin{array}{c}\text { Sig. (2- } \\
\text { Tailed) }\end{array}$ \\
\hline Imbalan & 0,59 & 0,000 \\
Pengawasan & 0,63 & 0,000 \\
Kondisi Kerja & 0,67 & 0,000 \\
$\begin{array}{l}\text { Pengembangan } \\
\text { Karier }\end{array}$ & 0,72 & 0,000 \\
Penghargaan & 0,70 & 0,000 \\
Kelompok & 0,60 & 0,000 \\
Kerja & & \\
Sumber: Hasil Penelitian, 2015 (data diolah)
\end{tabular}

Dari tabel 1 diatas hubungan antara imbalan dengan kepuasan kerja perawat pelaksana yaitu nilai $r=0,59$ dan nilai $p=0,0005$. Kesimpulan dari hasil tersebut: hubungan imbalan dengan kepuasan kerja perawat pelaksana menunjukkan korelasi kuat dan positif, artinya semakin tinggi kepuasan perawat pelaksana terhadap imbalan semakin tinggi kepuasan kerja perawat pelaksana. Hasil uji statistik didapatkan adanya hubungan yang signifikan antara kepuasan perawat pelaksana terhadap imbalan dengan kepuasan kerja ( $\mathrm{p}=0,0005)$. Menurut Darodjat (2015), imbalan yang diberikan dalam bentuk gaji atau insentif kepada karyawan atas kontribusi mereka dapat membantu organisasi untuk mencapai tujuan, apabila karyawan yang bekerja di organisasi tersebut merasa menerima imbalan secara adil. Adanya kejelasan rumah sakit dalam pemberian imbalan dalam penentuan besaran jumlah yang diberikan kepada perawat pelaksana dapat menyebabkan perawat pelaksana merasa hasil kerjanya dihargai.

Dari tabel 1 hubungan antara pengawasan dengan kepuasan kerja perawat pelaksana yaitu nilai $r=0,63$ dan nilai $p=0,0005$. Kesimpulan dari hasil tersebut: hubungan pengawasan dengan kepuasan kerja perawat pelaksana menunjukkan korelasi kuat dan positif, artinya semakin tinggi kepuasan perawat pelaksana terhadap pengawasan semakin tinggi kepuasan kerja perawat pelaksana. Hasil uji statistik didapatkan adanya hubungan yang signifikan antara kepuasan perawat pelaksana terhadap pengawasan dengan kepuasan kerja $(\mathrm{p}=0,0005)$. Fathoni (2006) menyatakan bahwa supervisi atau pengawasan, merupakan kegiatan manajer yang sangat penting dilakukan agar pekerjaan dapat terlaksana sesuai dengan apa yang telah ditetapkan atau sesuai dengan hasil yang dikehendaki, karena dengan adanya pengawasan yang baik maka akan meningkatkan kepuasan kerja dari karyawan.

Dari tabel 1 didapatkan hubungan antara kondisi kerja dengan kepuasan kerja perawat pelaksana yaitu hasil analisa diperoleh nilai $\mathrm{r}=$ 0,67 dan $\mathrm{p}=0,0005$. Kesimpulan dari hasil tersebut: hubungan kondisi kerja dengan kepuasan kerja perawat pelaksana menunjukkan korelasi kuat dan positif, artinya semakin tinggi kepuasan perawat pelaksana terhadap kondisi kerja semakin tinggi kepuasan kerja perawat pelaksana. Hasil uji statistik didapatkan adanya hubungan yang signifikan antara kepuasan perawat pelaksana terhadap kondisi kerja dengan kepuasan kerja $(\mathrm{p}=0,0005)$. Kondisi kerja yang aman, nyaman, bersih, penataan ruangan kerja yang rapi, fasilitas kerja yang baik, dan memadai mampu membawa dampak positif pada kinerja perawat pelaksana.

Hubungan antara pengembangan karier dengan kepuasan kerja perawat pelaksana nilai $\mathrm{r}=0,72$ dan $\mathrm{p}=0,0005$. Kesimpulan dari hasil tersebut: hubungan pengembangan karier dengan kepuasan kerja perawat pelaksana menunjukkan korelasi kuat dan positif, artinya semakin tinggi kepuasan perawat pelaksana terhadap pengembangan karier semakin tinggi kepuasan kerja perawat pelaksana. Hasil uji statistik didapatkan adanya hubungan yang signifikan antara kepuasan perawat pelaksana terhadap pengembangan karier dengan kepuasan kerja $(\mathrm{p}=0,0005)$. Hasil Penelitian Upenieks (2002) terhadap beberapa rumah sakit di Amerika Serikat yang hasilnya menunjukkan bahwa pada salah satu rumah sakit memiliki tingkat kepuasan kerja perawat lebih tinggi dari rumah sakit lainnya. Salah satunya dikarenakan adanya pengembangan tenaga keperawatan ditingkatkan oleh pihak rumah sakit seperti pendidikan yang berkesinambungan. Dimana orientasi karier dan pendidikan yang diberikan kepada tenaga keperawatan tidak dapat dipisahkan dengan kepuasan kerja.

Hubungan antara Penghargaan dengan kepuasan kerja perawat pelaksana Hasil uji statistik diperoleh nilai $\mathrm{p}=0,68>0,05$, artinya tidak ada hubungan bermakna antara pendapat terhadap penghargaan dengan kepuasan kerja. Pentingnya pemberian penghargaan dibuktikan dengan penelitian yang dilakukan Nolan et al (1995) dalam Gulick et al terhadap tenaga keperawatan di Inggris, dimana hasilnya menunjukkan kepuasan kerja menjadi meningkat ketika mereka merasa dihargai dan dihormati.

Jurnal Sains Riset | Volume VIII Nomor | 
Hubungan antara kelompok kerja dengan kepuasan kerja perawat pelaksana yaitu nilai $\mathrm{r}=$ 0,60 dan $\mathrm{p}=0,0005$. Kesimpulan dari hasil tersebut: hubungan kelompok kerja dengan kepuasan kerja perawat pelaksana menunjukkan korelasi kuat dan positif, artinya semakin tinggi kepuasan perawat pelaksana terhadap kelompok kerja semakin tinggi kepuasan kerja perawat pelaksana. Hasil uji statistik didapatkan adanya hubungan yang signifikan antara kepuasan perawat pelaksana terhadap kelompok kerja dengan kepuasan kerja $(p=0,0005)$. Davis et.al.(2007) menjelaskan bahwa, faktor hubungan antar pribadi seperti kerjasama dalam kelompok kerja memiliki pengaruh yang sangat tinggi terhadap kualitas pekerjaan. Luthans (2006) menyatakan bahwa bagi seorang karyawan komunikasi atau interaksi dengan rekan kerja yang relatif sama statusnya pada level organisasi yang sama memberikan dukungan sosial yang mereka perlukan. Seorang tenaga keperawatan merasa lebih nyaman dengan dukungan dari rekan kerja, dari pada dukungan dari orang yang ada dibawah atau diatas mereka.

\section{Tabel 2. Model Akhir Dari Analisa} Multivariat

\begin{tabular}{|c|c|c|c|c|c|c|c|}
\hline \multirow[b]{2}{*}{ Xthed $=1$} & \multicolumn{2}{|c|}{ 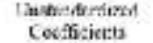 } & \multirow{2}{*}{ 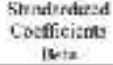 } & \multirow[b]{2}{*}{1} & \multirow[b]{2}{*}{ Sit - } & \multicolumn{2}{|c|}{$\begin{array}{l}\text { Collinutaty } \\
\text { Ststiztices }\end{array}$} \\
\hline & "1 & atd linor & & & & Inberanes & VII \\
\hline (Comentort) & 7,008 & 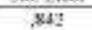 & & 9,352 & 1000 & & \\
\hline Imsalen & $\therefore \infty$ & $15 i$ & -441 & $-1.15 s^{2}$ & 104 & 62 & f. 1 ลล \\
\hline Trngementm & $-\pi \%$ & 137 & $-16 i$ & .562 & $5 \pi$ & 136 & 7.317 \\
\hline Kiven is Kejp & ma & $\Delta=\pi$ & 152 & 731 & $\Delta 3$ & 6r: & 6,015 \\
\hline $\begin{array}{l}\text { Pengenburge } \\
\text { Fariver }\end{array}$ & .39a & ose & AGg & $2.58 !$ & ath & 93 & $5,0,07$ \\
\hline 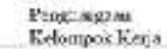 & Jil & 109 & 292 & int & $\frac{536}{20}$ & 47 & $\begin{array}{l}5,551 \\
6,584\end{array}$ \\
\hline
\end{tabular}

Sumber: Hasil Penelitian, 2015 (data diolah)

Nilai yang didapatkan dalam penelitian ini yaitu ( $\mathrm{R}$ square) menunjukkan nilai 0,554 artinya bahwa model regresi yang diperoleh dapat menjelaskan bahwa $55,4 \%$ variasi variabel dependen yaitu kepuasan kerja perawat pelaksana (Y) pada model dapat diterangkan oleh variabel independen yaitu: imbalan (X1), pengawasan (X2), kondisi kerja (X3), pengembangan karier (X4), penghargaan (X5) dan kelompok kerja (X6). Hasil uji $\mathrm{F}$ menunjukkan nilai $\mathrm{P}$ $($ sig $)=0.0005$, berarti pada alpha $5 \%$ kita dapat menyatakan bahwa model regresi cocok (fit) dengan data yang ada. Atau dapat diartikan imbalan, pengawasan, kondisi kerja, pengembangan karier, penghargaan dan kondisi kerja dapat untuk memprediksi kepuasan kerja perawat pelaksana. Pada kotak coefficient kita dapat memperoleh persamaan garis B (di bagian
Variabel in equation) pada tabel1, kita dapat mengetahui koefisien regresi masing-masing variabel. Dari tabel 2 persamaan regresi yang didapat adalah:

$$
\begin{aligned}
& \mathrm{Y}=\quad 7,708-0,299 \mathrm{X} 1-0,096 \mathrm{X} 2- \\
& +0,198 \mathrm{X} 4+0,063 \mathrm{X} 3 \\
& \text { Dimana : } \\
& \mathrm{Y}=\text { Kepuasan Kerja } \\
& \mathrm{X} 1=\text { Imbalan } \\
& \mathrm{X} 2=\text { Pengawasan } \\
& \mathrm{X} 3=\text { Kondisi Kerja } \\
& \mathrm{X} 4=\text { Pengembangan Karier } \\
& \mathrm{X} 5=\text { Penghargaan } \\
& \mathrm{X} 6=\text { Pengembangan Karier } \\
&
\end{aligned}
$$

kesimpulan bahwa:

1. Pada model regresi ini, nilai konstanta diperoleh sebesar 7,708 atau berpengaruh positif terhadap kepuasan kerja.

2. Apabila terjadi satu peningkatan nilai dari imbalan maka variabel kepuasan kerja akan menurun sebesar 0,299.

3. Apabila terjadi satu peningkatan nilai dari pengawasan maka variabel kepuasan kerja akan menurun sebesar 0,096.

4. Apabila terjadi satu peningkatan nilai dari kondisi kerja maka variabel kepuasan kerja akan meningkat sebesar 0,063.

5. Apabila terjadi satu peningkatan nilai dari pengembangan karier maka variabel kepuasan kerja akan meningkat sebesar 0,198 .

6. Apabila terjadi satu peningkatan nilai dari penghargaan maka variabel kepuasan kerja akan meningkat sebesar 0,101 .

7. Apabila terjadi satu peningkatan nilai dari kelompok kerja maka variabel kepuasan kerja akan meningkat sebesar 0,111 .

Dari kolom Beta pada tabel 2 dapat kita gunakan untuk mengetahui variabel independen (imbalan, pengawasan, kondisi kerja, pengembangan karier, penghargaan, kelompok kerja) mana yang mempunyai pengaruh dominan terhadap variabel dependen (kepuasan kerja). Semakin besar nilai beta variabel independen semakin dominan pengaruhnya terhadap variabel dependen. Jadi dapat disimpulkan bahwa pengembangan karier mempunyai pengaruh paling dominan terhadap kepuasan kerja perawat pelaksana di ruang rawat inap RSUD Tgk. Chik Ditiro Sigli.

Kesempatan untuk pengembangan karier bagi setiap karyawan yang berdasarkan atas azas keadilan dan objektivitas akan mendorong 
karyawan untuk bekerja lebih giat, bersemangat, berdisiplin dan berprestasi kerja yang semakin besar sehingga tujuan organisasi yang optimal dapat tercapai (Fathoni, 2006). Pengembangan karier perawat pelaksana tidak akan berjalan dengan baik apabila tidak ada kesempatan dari pimpinan untuk meningkatkan pengetahuan dan keterampilan baik melalui pelatihan maupun peningkatan jenjang pendidikan. Keputusan Menteri Negara Pendayagunaan Aparatur Negara No. 94/kp/M.Pan/XI/2001 tentang jabatan fungsional perawat dan angka kreditnya, merupakan salah satu sistem jenjang karier bagi perawat PNS. Pola karir PNS ini menggambarkan jalur pengembangan karier dan menunjukkan keterkaitan dan keserasian antar pejabat, pangkat, pendidikan dan pelatihan struktural dan fungsional serta masa jabatan pegawaian negeri sipil sejak masa pengangkatan hingga pensiun (Wardhani dan Simanjuntak, 2003).

Dalam kebijakan pemerintah jabatan fungsional perawat terdiri dari dua kelompok yaitu perawat ahli dan perawat terampil. Pengembangan sistem jenjang karier melalui jabatan fungsional ini lebih berorientasi kepada posisi (jabatan), sedangkan sistem jenjang karier profesional ini lebih kearah jenjang karier profesional. Berdasarkan peran dan fungsi perawat, maka sistem jenjang karier perawat dapat dikembangkan dalam empat kelompok yaitu: perawat klinik, perawat manajer, perawat pendidik dan perawat peneliti (Wardhani dan Simanjuntak, 2003). Kondisi tersebut menjadi keinginan PPNI sebagai wadah resmi perawat di Indonesia. PPNI bertujuan agar diterapkannya sistem reward dan jenjang karier profesional bagi perawat yang didukung oleh sistem pendidikan dan pelatihan yang berkelanjutan (INNA, 2002). Karena menjadi suatu kebanggaan bagi tenaga keperawatan, jika mereka diberi kesempatan untuk meningkatkan kemampuan dan menduduki jabatan yang lebih tinggi. Jabatan yang diberikan baik dalam struktural maupun jabatan fungsional. Oleh karena itu, sangat penting bagi rumah sakit untuk memperhatikan dan memenuhi pengembangan karier mereka (Domrose, 2001) dalam Perry, 2008).

Promosi karier memberikan peranan penting bagi setiap perawat pelaksana, bahkan menjadi idaman yang selalu diharapkan oleh semua perawat pelaksana karena dengan pengembangan karier berarti adanya kepercayaan dan pengakuan dari rumah sakit mengenai kemampuan serta kecakapan yang bersangkutan untuk menjabat suatu jabatan yang lebih tinggi sesuai kemampuan yang dimiliki.

\section{KESIMPULAN}

1. Pada analisa univariat didapatkan, kepuasan kerja perawat pelaksana, imbalan, pengawasan, kondisi kerja, penghargaan, pada kategori puas. Pengembangan karier, dan kelompok kerja kelompok kerja pada kategori sangat puas. Dan kepuasan kerja pada kategori puas.

2. Pada analisa bivariat didapatkan imbalan, pengawasan, kondisi kerja, pengembangan karier, penghargaan dan kelompok kerjamenunjukkan korelasi kuat dan positif terhadap kepuasan kerja. Hasil uji statistik didapatkan adanya hubungan yang signifikan antara semua variabel independen dengan variabel dependen $(\mathrm{p}=0,0005)$.

3. Pada analisa multivariat pada uji serempak didapatkan variabel seluruh variabel independen (imbalan, pengawasan, kondisi kerja, pengembangan karier, penghargaan dan kelompok kerja) berpengaruh terhadap kepuasan kerja perawat rawat inap di RSUD Tgk. Chik Ditiro Sigli tahun2015. Dari uji parsial seluruh variabel independen terhapad dependen, didapatkan hasil yang dominan berpengaruh adalah pengembangan karier.

\section{SARAN}

1. Bagi pimpinanan RSUD Tgk. Chik Ditiro Sigli dan jajaran manajemen RS agar pengembangan karier di RS ini semakin baik maka perlu, mengembangkan pelaksanaan sistem promosi karier yang baik berdasarkan peraturan yang ada, adanya kesempatan yang sama bagi semua tenaga keperawatan yang sudah memenuhi persyaratan untuk dipromosikan, adanya kemudahan-kemudahan dalam kenaikan pangkat sesuai peraturan yang ada, mengalokasikan dana cadangan rumah sakit untuk pelatihan dan pendidikan perawat pelaksana.

2. Bagi pimpinan RSUD Tgk. Chik Ditiro Sigli dapat memberikan pelatihan tentang pengembangan karier kepada bagian kepegawaian, mengingat pentingnya bagian kepegawaian harus selalu 
mengetahui perkembangan terbaru tentang peraturan pengembangan karier.

3. Untuk meningkatkan mutu pelayanan perawat pelaksana yaitu dengan cara perawat pelaksana melakukan praktik keperawatan yang aman, kompeten dan profesional bagi masyarakat.

4. Untuk para peneliti selanjutnya disarankan agar penelitian sejenis dapat dilakukan dengan menambahkan variabel independen yang lebih luas.

\section{DAFTAR PUSTAKA}

Darojat, Tubagus, 2015. Konsep-Konsep Dasar Manajemen Personalia Masa Kini. PT. Refika Aditama: Bandung

Davis et al., 2007. 'Comparison of Job Satisfaction Between Experienced Medical-Surgical Nurses and Experienced Critical Care Nurses', Journal of Medsurg Nursing, Online. vol. 16 , no. 5 , pp. 311-316, pp. 311-316. Dari

$$
\text { : }
$$
Proquest. http://www.proquest.com/pqdweb/ Juli 2015)

Fathoni, A. 2006. Organisasi dan Manajemen Sumber Daya Manusia. Rineka Cipta: Jakarta

Gillies, DA. 1996. Manajemen keperawatan suatu pendekatan sistem. Rineka Cipta: Jakarta

INNA, 2002. INNA Business Plan 2002-2010. Central Board INNA: Jakarta

Kaplan \& Norton, 1996. Translating Strategy Into Action The Balanced Scorecard. Harvard Business School Press: Boston

Luthans, F. 2006. Perilaku Organisasi, Edisi Sepuluh. Alih Bahasa Yuwono dkk, Andi. BPFE: Yogyakarta

Marquis, B.L., \& Huston, C. J. (2010). Kepemimpinan
ManajemenKeperawatan: Teori dan Aplikasi. EGC: Jakarta

Permenpan, 2012. Peraturan Menteri Pendayagunaan Aparatur Negara Nomor 10 Tahun 2012 Tentang Sistem Pengawasan Internal Pemerintah. Permenpan RI: Jakarta

Perry, Beth. 2008. 'Shine On: Achieving Career Satisfaction as a Registered Nurse', The Journal of Continuing Education in Nursing. Online. vol. 39, no. 1, pp. 1725. Dari : Proquest. http://www.proquest.umi.com/pqdweb/ (28 Juli 2015)

Robbins, S.P. 2008. Organization Behavior: Concept, Controversies, Apllications (Perilaku Organisasi, Konsep Kontravesi, Apliaksi). Jilid 1, Alih Bahasa Pujatmaka , Handayana \& Molan, B. Prenhallindo: Jakarta

Soeroso, S. 2003. Manajemen Sumber Daya Manusia di Rumah Sakit. Suatu Pendekatan Sistem. EGC: Jakarta

Upenieks, Valda V. 2002, 'Assessing Differences in Job Satisfaction of Nurses in Magnet and Nonmagnet Hospitals', Journal of Nursing Administration, Online, vol 32, no. 11, pp. 564-576. Dari : http://www.nursingcenter.com. (26 Jan 2008)

Wardhani dan Simanjuntak, 2003. Jenjang Karir Tenaga Keperawatan. Jurnal Manajemen dan Administrasi Rumah Sakit Indonesia, Vol. 4. No. 2, April 2003.

Winardi. J, 2004. Manajemen Perilaku Organisasi, Edisi Revisi. Prenada Media: Jakarta 